\title{
Cosmetic Disfigurement due to Home Remedy in Melanocytic Nevi
}

\author{
Riya Kaur Kalra, ${ }^{1}$ Phulwinder Singh ${ }^{2}$
}

\author{
Introduction \\ Melanocytic nevi of the head and neck region are common among all ages with no predilection for males or females. These moles \\ can appear as small, dark brown spots on the skin anywhere on the face including the eyelids, which may not be cosmetically \\ acceptable. \\ Case Report \\ Here we report a case where a toilet cleaner (tezaab) was used to remove the facial mole leading to scar formation, which \\ otherwise could have been removed with various latest modalities with no residual scar. \\ Discussion \\ Melanocytic nevi can be removed safely by the latest modalities available by the trained professionals but at times people try \\ home remedies or take internet suggestions before consulting a doctor which can lead to ugly scars. \\ Keywords \\ Nevus; Pigmented; Moles; Cicatrix
}

$\underline{\text { ABSTRACT }}$

$\mathrm{N}$ evi or moles are benign tumors composed of nevus cells that are derived from melanocytes. Moles are so common that they appear virtually on every person. They are present in $1 \%$ of newborns and increase in incidence throughout infancy and childhood. ${ }^{1}$ On the basis of size, they are categorized as small (diameter $<1.5 \mathrm{~cm}$ ), medium $(1.5$ to $19.9 \mathrm{~cm}$ ) and large $(>20 \mathrm{~cm})^{2}$

Melanocytic nevi of the head and neck region are common among all ages with no predilection for males or females. These moles can be anywhere on the face including the eyelids. Main reason for removal is suspected melanoma; other reasons for removal are cosmetic, or because a raised mole interferes with daily life (e.g. shaving). ${ }^{3}$

Moles can be removed in the office under local anesthesia by different methods (chosen depending on the size of the lesion) like punch biopsy, shave excision, radiosurgery. ${ }^{4}$

Here we report a case where a toilet cleaner (tezaab) was used to remove the facial mole leading to scar formation, which otherwise could have been removed with various latest modalities with no residual scar.

\section{Case Report}

A 12-year old female patient presented in the outpatient department for the mutilated lesion over her forehead. (Fig. 1) Her attendant gave the history of the presence of a mole over the forehead in-between the eyebrows since birth which increased to present size in the past few months.

There was history of application of Tezaab (acid used to clean rust from tools and toilets), as told by the attendant, by her paternal grandmother three days back which was followed one day later by purulent discharge from the lesion. The child was lucky enough to avoid any injury to the eye as the procedure was done by the untrained person. After examination in the chamber she was managed with topical, oral antibiotics and antiinflammatory medicines and the lesion healed with scar

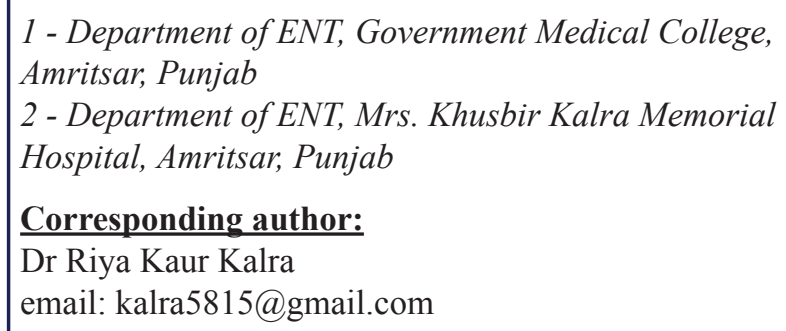




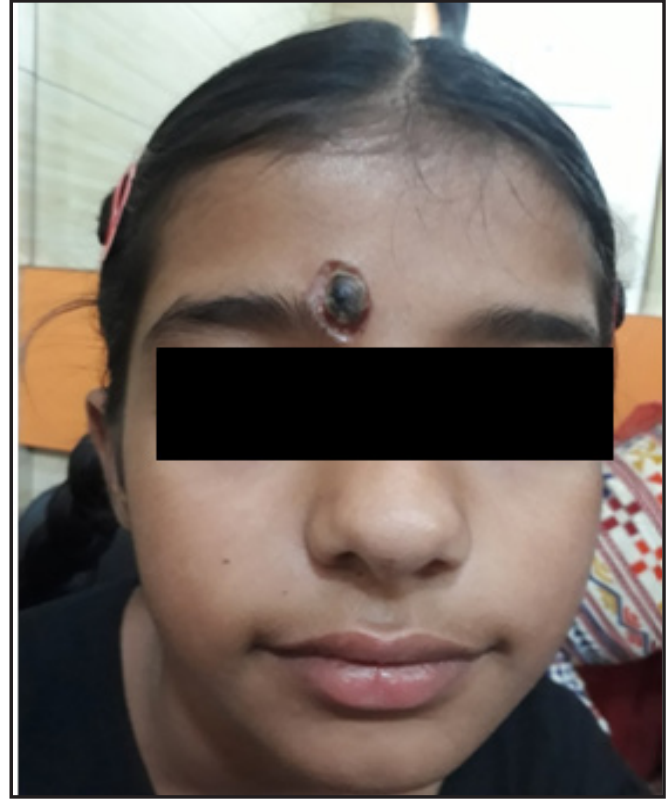

Fig. 1. The clinical photograph on presentation

formation. (Fig. 2)

\section{Discussion}

Melanocytic nevi are common lesions in patients with light or fair skin with genetic basis. Exact etiology behind the development of melanocytic nevi is complex and multifactorial. At times they are stimulated by exposure to sunlight or hormone changes. Patients should be educated regarding self-examination of nevi, in which the patient assesses the asymmetry, border irregularity, color, diameter (size), and evolution of any given lesion (ABCDE approach). Nevi can change in diameter, outline, color and they can acquire an itch or begin to bleed. These changes require evaluation by a trained observer to determine the malignant potential of the lesion. ${ }^{5}$

To determine the prognosis and treatment modalities, it is essential to know whether the nevus is congenital or acquired. ${ }^{6}$ Congenital melanocytic nevus differs from acquired by its presence at birth with the tendency for larger size and greater malignant potential. ${ }^{7}$

Congenital nevi are found in about $1 \%$ of the newborn infants. They are usually solitary and their

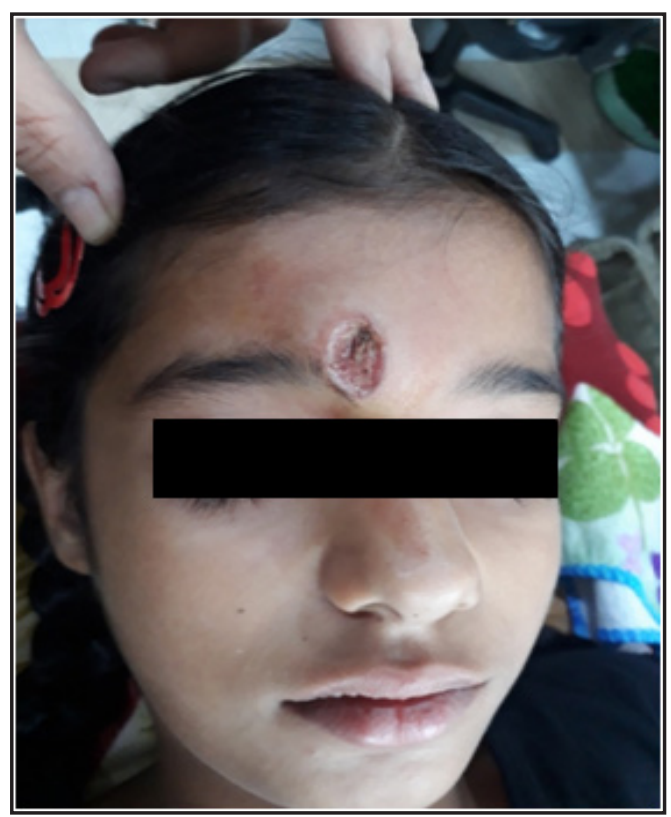

Fig. 2. The scar after healing

growth is very rapid and disproportionate to the growth of the particular body area in the first six months of life thereafter it remains static unless there is infection, trauma or development of malignancy. ${ }^{8}$

There are many home remedies from our grandmother's book or internet which people try before consulting a doctor. These are simple kitchen ingredient like baking soda, juice of garlic, onion, sour apple, pineapple, lemon, potato, tomatoes. Flaxseed and linseed oil, root of dandelion herb is rubbed over mole. ${ }^{9}$, 10

Homeopathy treatments are also available such as Pulsatilla, Aceticum acidum, Floricum acidum, Phosphorus, Thuja occidentalis, Calcareacarbonica, Sulphur, Carbo vegetabilis, Graphites, Lycopodium, Petroleum, Sepia, Radium bromatum, Carcinosin, Medorrhinum, Cundurago, Platina. ${ }^{11}$

Medical treatment is typically ineffective and inappropriate for the management of a benign neoplasm such as a melanocytic nevus. Melanocytic nevi can be surgically removed for cosmetic considerations or because of concern regarding the biological potential of a lesion. Hence these cases should be referred to the concerned physician for the appropriate management. ${ }^{12}$ 


\section{Conclusion}

In 21 st century there is a variety of choice of treatment modalities for the removal of nevi and with proper selection of the procedure, good cosmetic results can be achieved. Although cases of melanocytic nevi are very common, yet they are less reported in the reputed journals. Hence, considering the above case it's the duty of the medical fraternity to create awareness for not using home remedies which can lead to scars that are traumatic for both body and mind.

We report this case firstly to illustrate the ignorance of people regarding the consequences of their actions and secondly there is no mention of such a case in the literature to the best of our knowledge.

\section{References}

1. Habif TP. Nevi and Malignant Melanoma. In: Clinical Dermatology: A color guide to diagnosis and therapy. 5th ed. Gurgaon: Elsevier Publishers; 2010. p. 847

2. Tannous ZS, Mihm MC, Sober AJ, Duncan LM. Congenital Melanocytic nevi: clinical and histopathological features, risk of melanoma and clinical management. J Am Acad Dermatol. 2005; 52:197-203

3. Melanocytic Nevus. [Online]. 1 Nov 2017 [cited 10 Jan
2018]; Available from: URL: https://en.wikipedia.org/wiki/ Melanocytic_nevus

4. Sacchidanand S, Ramachander T. Melanocytic Nevi: Treatment Modalities. In: ACS(I) Textbook on Cutaneous \& Aesthetic Surgery. 1st ed. London: Jaypee Brothers Medical Publishers; 2012. p. 281-8

5. McCalmont T. Melanocytic Nevus. [Online]. 6 Oct 2016 [cited 18th Oct 2017]; Available from: URL: https://emedicine. medscape.com/article/1058445-overview

6. Hoss DM, Grant-Kels JM. Significant melanocytic lesions in infancy, childhood and adolescence. Dermatol Clin. 1986; 4:29-44

7. Rhodes AR, Silvermann RA, Harrist TJ, et al. A histologic comparison of congenital and acquired nevo-melanocytic nevi. Arch Dermatol. 1985; 121:1266-73

8. Osburn K, Schosser RH, Everett MA. Congenital pigmented and vascular lesions in newborn infants. J Am Acad Dermatol. 1987; 16:788-92

9. Conditions Moles. [Online]. [cited 26th Oct 2017]; Available from: URL; http://www.naturalremedies.org/moles/

10. Kafeel B. Homeopathic treatment for moles. [Online]. $29 \mathrm{Jul}$ 2011 [cited 25 Oct 2017]; Available from: URL: http://www. onlymyhealth.com/ayurvedic-treatment-moles-1311918375

11. Ezine H. Homeopathy for moles/Naevus. [Online]. May 2014 [cited 21 Oct 2017]; Available from: URL: https://treatment. hpathy.com/homeo-medicine/homeopathy-moles-naevus/

12. McCalmont T. Melanocytic Nevi Treatment \& Management. [Online]. 6 Oct 2017 [cited 23 Oct 2017]; Available from: URL: http://emedicine.medscape.com/article/1058445-treatment\#d6. 